NBER WORKING PAPER SERIES

\author{
OPTIMAL TAXATION BY THE \\ MONETARY AUTHORITY
}

Carl E. Walsh

Working Paper No. 1375
NATIONAL BUREAU OF ECONOMIC RESEARCH
1050 Massachusetts Avenue
Cambridge, MA 02138
June 1984

I would like to thank Alan Blinder, Jeffery Carmichael, Larry Kantor, Karlyn Mitchell, Douglas Pearce, and Harvey Rosen for helpful comments. The research reported here is part of the NBER's research program in Financial Markets and Monetary Economics. Any opinions expressed are those of the author and not those of the National Bureau of Economic Research. 
NBER Working Paper \#1375

Optimal Taxation by the Monetary Authority

\section{ABSTRACT}

Reserve requirements imposed against bank deposits, nominal interest payments on bank reserves (or on base money), and inflation can all be viewed as generating tax effects. Any analysis of optimal monetary policy in a steady-state equilibrium needs to consider the simultaneous choice of all the tax instruments controlled by the monetary authority. Such an analysis is carried out in this paper. It is shown that when the tax system is not indexed, the optimal nominal interest rate on the monetary authority's liabilities is likely to be zero. More important$1 y$, any discussion of the payment of interest on reserves and currency must take into account the nature of the tax system and the rate of inflation in a nonindexed economy.

Carl E. Walsh

Department of Economics

Princeton University

Princeton, NJ 08544

(609) $452-4026$ 


\title{
OPTIMAL TAXATION BY THE MONETARY AUTHORITY
}

\begin{abstract}
Economists often analyze monetary policy in steady state equilibria by treating the rate of inflation as a tax (Johnson[1968], Friedman[1969], Phelps[1973], Marty[1978], Drazen[1979], Summers[1981]). Higher rates of inflation increase the opportunity cost of holding noninterest bearing money, leading individuals to reduce their real money balances. By viewing inflation as a tax on liquidity, it is possible to draw on the optimal taxation literature in analyzing the rate of inflation that would maximize the steady state utility of a representative individual (Phelps[1973], Drazen[1979]).
\end{abstract}

The rate of monetary expansion, and hence inflation, is not the on $1 y$ policy instrument available to the monetary authority, nor is it the only policy instrument which can be viewed as generating tax effects. Reserve requirements imposed against bank deposits, for example, act as a tax on the holding of such deposits (Fama[1980]). In addition, if the tax system is not indexed, changes in the rate of inflation influence the effective tax rate on real capital (Feldstein[1976], Summers[1981]). This in turn implies that the payment of nominal interest on money is generally not a perfect substitute for a steady state rate of deflation as a means of achieving a given real return on money. The tax on capital will depend on the composition of the real return on money between nominal interest payments and deflation. 
If the monetary authority can affect the rates of taxation on capital, liquidity, and deposits through the use of its policy instruments, then any analysis of optimal, steady state monetary policy needs to consider the simultaneous choice of all the authority's instruments. The purpose of this paper is to carry out such an analysis. It is shown that with a nonindexed tax system, it may not be optimal for the central bank to pay interest on its liabilities.

The basic framework utilized to study optimal policy is presented in section II. Discussed in that section is the choice problem of the representative consumer who must allocate income between consumption and saving and must allocate wealth between capital, bank deposits, and money. Section III considers the case in which the monetary authority can pay an explicit rate of return on base money (reserves plus currency). The case in which explicit interest on currency is not technologically feasible is treated in section IV. Section $V$ is a brief summary of the paper's results. The next section reviews the previous literature on optimal inflation.

\section{BACKGROUND}

Initial analyses of the optimal rate of inflation utilized a partial equilibrium framework (e.g., Friedman[1969]). Optimality was achieved when the private opportunity cost of holding money was equal to the social cost of producing money. Assuming the latter cost to be zero and the former cost to be the nominal rate of interest, the basic result was that optimality would be achieved with a zero nominal rate of interest. 
The optimal rate of deflation was then equal to the real rate of interest. If an explicit rate of interest was paid on nominal money balances, the optimality condition simply required that the real rate of return on money equal the real rate of return on capital. Letting $r_{k}$ denote the real return on capital, $\pi$ the steady state rate of inflation, and $i$ the policy determined nominal return on money, equating $i-\pi$ to $r_{k}$ defines a linear combination of values for $i$ and $\pi$ which achieve the optimum degree of liquidity.

Subsequent analyses of the optimal rate of inflation generally focused on the partial equilibrium nature of the above result. The most influential has been the argument made by Phelps [1973] ${ }^{1}$ that the Friedman result implicitly assumes the existence of lump-sum taxes. If such nondistortionary taxes are not available, and if the analysis of a change in the rate of inflation is carried out under the assumption that total government revenue must remain fixed, then the optimal rate of inflation may result in a positive tax on real money balances. The intuition behind this result is quite simple; if only distortionary taxes can be used to meet a fixed revenue requirement, deviations from the first order efficiency conditions will generally be required for all goods (Sandmo[1976]). Recognition of the need to simultaneously consider the setting of the inflation tax together with other distortionary taxes led to the use of optimal tax models to study the question of the optimal rate of inflation (Phelps[1973], Marty[1978], and Drazen[1979]).

An alternative approach has focused on the Tobin effect whereby changes in the rate of inflation lead to variations in the steady state 
capital-labor ratio. If money is not superneutral, and if the existing capital-labor ratio is below the golden rule value that maximizes steady state per capita consumption, a higher rate of inflation may lead to an increase in welfare by raising the capital-labor ratio. Welfare may rise even though the higher inflation increases the inefficiencies due to the divergence between money's social cost of production and its private opportunity cost. This effect has been emphasized by summers [1981]. ${ }^{2}$ However, this conclusion is called into question by the results of Stockman[1981] who shows that a rise in the rate of inflation may reduce the steady state capital-labor ratio in an economy facing a clower cash-in-advance constraint (Clower[1967]).

A number of authors (Feldstein[1976], Green and Sheshinski[1977], Summers [1981]) have pointed out that inflation can have real effects due to the nonneutrality of the tax system. Although specific conclusions depend on the nature of the nonindexation of the tax system, the optimal rate of inflation will generally not be that associated with a zero opportunity cost of holding money.

Previous authors have dealt only with the case in which all money is a liability of the central bank (see Summers[1981] for an exception). In the absence of privately produced money, it has also been convenient to assume that money earns no explicit interest. Once inside money is introduced, a number of new issues arise which have not previously been systematically analyzed. If deposits supplied by the banking industry pay a competitively determined rate of interest while outside money does not, the wedge between the rates of return on the two types of money 
will depend on the rate of inflation. The wedge will also be affected by any reserve requirement that forces banks to hold non-interest bearing reserves. Further effects arise if inflation has a direct effect on the return to capital because of a nonindexed tax system. In this case, all values of $i$ and $\pi$ for which $i-\pi=r_{k}$ are not equivalent since $\pi$ affects the wedge between the returns on capital and base money (reserves plus currency). The optimal rate of inflation will also depend on whether the central bank pays interest on base money or only on reserves.

In the model to be analyzed in this paper, the monetary authority is viewed as having three policy tools: the steady state rate of inflation, a reserve requirement ratio, and the interest rate paid on bank reserves (or reserves plus currency). The monetary authority is also assumed to be subservient to the fiscal authority in that any deficit implied by the fiscal authority's choice of tax rates and spending level must be financed through what can be described as monetary policy revenue sources. Because all three policy instruments affect the revenue generated by monetary policy, their optimal values must generally be jointly determined. For example, the optimal rate of inflation will not be independent of the choice of the reserve requirement ratio.

\section{THE MODEL}

The basic framework is a neoclassical growth model populated by identical individuals with infinite planning horizons, profit maximizing firms operating in perfectly competitive markets, and pure financial intermediaries called banks. 


\section{a) Individuals}

Individual behavior is assumed to be directed towards maximizing, subject to constraints, $\int_{0}^{\infty} u_{t} e^{-\delta t} d t$, where $u_{t}$ is the instantaneous level of utility at time $t$ and $\delta$ is the subjective rate of time preference. Instantaneous utility is given by $u\left(c_{t}\right)$ where $c_{t}$ is the rate of per capita consumption of the single good produced in this economy.

Individuals maximize total utility subject to two types of constraints. The first is a budget constraint. Each individual is assumed to supply a fixed amount (one unit) of 1 abor and to receive a real wage income of $\mathrm{w}$. In addition, individuals earn a nominal pre-tax return of $r_{k}+\pi$ per unit of capital, while the nominal interest rates on deposits and base money are $i_{d}$ and $i$ respectively. Initially it will be assumed that the monetary authority can pay $i$ on both reserves and currency. Section IV examines the case in which $i$ is paid only on reserves.

The budget constraint faced by the individual depends on the structure of taxes which, for simplicity, are assumed to be levied only on households. If nominal personal income (including nominal capital gains) is taxed at the rate $\tau$, after tax, real, per capita income equals $(1-\tau)\left[w+\left(r_{k}+\pi\right) k+i_{d} d+i m\right]-\pi[k+d+m]$ where $k, d, m$ are real per capita holdings of capital, deposits, and currency. Feldstein[1976], Green and Sheshinski[1977], and Auerbach[1983] show how the interaction of inflation and the tax system may fail to be adequately represerted by a simple formulation that assumes the real returns to capital are taxed at the same rate as nominal capital gains. To keep the present analysis 
uncomplicated yet allow a bit more generality, the tax rate on nominal capital gains on individuals' holdings of capital will be allowed to differ from the rate applied to other components of income. Hence, after tax real per capita income is defined as $\left(1-\tau_{1}\right)\left[w+r_{k} k+i_{d} d+i m\right]+$ $\left(1-\tau_{2}\right) \pi k-\pi[k+d+m]$.

In order to adopt a specification which makes money essential to the economy, a modified Clower-cash-in-advance constraint will be assumed to hold (see Clower[1967]). That is, an individual's current spending plans are limited by current holdings of cash and deposits. Rather than writing this constraint as $m+d \geq c+\dot{k}$ where $a \cdot$ denotes a time derivative, a more general specification will be used to capture the notion that cash and deposits may not be perfect substitutes in the carrying out of all transactions. The transaction technology will be represented by a constraint of the form

$$
h(m, d) \geq c+\dot{k}
$$

where $h()$ is a concave, twice continuously differentiable function which can be thought of as a liquidity production function. It is assumed that $h_{m}>0, h_{d}>0, h_{m m} \leq 0$, and $h_{d d} \leq 0 .^{3}$

The representative individual is assumed to maximize total utility subject to a budget constraint which, when the rate $i$ is paid on both bank reserves and currency, can be written as ${ }^{4}$ 
(2) $\left(1-\tau_{1}\right)\left[w+r_{k} k+i_{d} d+i m\right]+\left(1-\tau_{2}\right) \pi k-(n+\pi)[k+d+m]-c-\dot{k}-\dot{d}-\dot{m}=0$

where $\mathrm{n}$ is the exogenous rate of population growth.

Assuming an interior solution in which individuals hold all three assets and considering only steady states in which $\dot{k}=\dot{d}=\dot{m}=0,5$ the first order conditions for the maximization of utility subject to the budget constraint ( 1 ) and the liquidity constraint (2) can be written as

$$
u^{\prime}(c)=\mu+\lambda
$$

$$
\lambda h_{m}=\mu(\delta+n-r)
$$

$$
\lambda h_{d}=\mu\left(\delta+n-r_{d}\right)
$$

together with (1) and (2) with equality, where $\mu$ and $\lambda$ are the Lagrangian multipliers associated with the income and liquidity constraints respectively, and $r=\left(1-\tau_{1}\right) i-\pi$ and $r_{d}=\left(1-\tau_{1}\right) i_{d}-\pi$ are the real, after tax returns on currency and deposits.

\section{b) Firms}

Firms are assumed to operate in competitive factor and output markets. The economy's productive technology is summarized by a neoclassical production function, taken to be homogeneous of degree one in capi- 
tal and labor. Thus, per capita output is given by $f\left(k^{a}\right)$ with $f^{\prime} \geq 0$, $f^{\prime \prime} \leq 0$, where $k^{a}$ is the aggregate stock of capital per capita.

The assumption that firms are competitive and maximize profits implies that workers are paid their marginal product and that capital is hired to the point where its marginal product equals $r_{k}$. Hence,

$$
w=f\left(k^{a}\right)-f^{\prime}\left(k^{a}\right) k^{a}
$$

$$
r_{k}=f^{\prime}\left(k^{a}\right)
$$

\section{c) Banks}

\section{Banks are taken to be pure financial intermediaries (see Fama[1980]), producing deposits at constant marginal cost (assumed equal to zero for simplicity). On the asset side of their balance sheets, banks hold cap- ital and reserves. It is assumed that banks, like nonfinancial firms, are not taxed directly by the fiscal authority. However, banks must hold a fraction $p$ of their deposits in the form of reserves. Excess re- serves are taken to be zero. All income generated by bank assets is paid out to depositors. This implies}

(9) $i_{d}=p i+(1-p)\left(r_{k}+\pi\right)$.

\section{d) Equilibrium}


Using equations (3)-(9), the economy's steady state equilibrium is characterized by

$$
\psi h_{m}=\delta+n-r
$$

(11) $\psi \mathrm{h}_{\mathrm{d}}=\rho(\delta+n-r)+(1-\rho)\left[\left(\tau_{1}-\tau_{2}\right) \pi-\delta \psi\right]$

$$
\left(1-\tau_{1}\right) f^{\prime}\left(k^{a}\right)-\tau_{2} \pi=\delta(1+\psi)+n
$$

$$
h(m, d)=\left(1-\tau_{1}\right) f\left(k^{a}\right)-\left(\tau_{2} \pi+n\right) k^{a}+(1-p)\left(\tau_{2}-\tau_{1}\right) \pi d+(r-n)(m+p d)
$$

where $k^{a}=k+(1-p) d$ is the aggregate capital stock in the economy, and $\psi=\lambda / \mu . \quad \psi$ is equal, then, to the shadow price of transaction services relative to the shadow price of income.

The equilibrium conditions (10)-(13) each have a straightforward interpretation. Equations (10)-(12) require that the net of tax returns on all assets equal $\delta+n$. The form of the after tax return, however, is different for each asset. Currency, for example, yields an explicit after tax interest return of $r$. It also produces liquidity services with the marginal productivity of currency in the production of such services given by $h_{m}$. The value of these services is $\psi h_{m}$ so that the total return to currency is $\psi \mathrm{h}_{\mathrm{m}}+r$, and (10) says this is equated to $\delta$ $+n$ if currency is held.

The return on deposits has three components. On unit of real deposits represents a claim on $\rho$ units of currency in the form of bank reserves 
and $(1-\rho)$ units of bank held capital. Deposits also produce liquidity services valued at $\psi h \mathrm{~h}$. The total after tax return on deposits is then $\psi h_{d}+\rho r+(1-\rho)\left(1-\tau_{1}\right)\left(f^{\prime}+\pi\right)$. Setting this equal to $\delta+n$ and rear ranging, using (12), yields (11).

Equation (12) equates the net of tax return on directly held capital to $\delta+n$, while (13) is just the budget constraint with c replaced by $h(m, d)$ since (2) will be binding along the optimal consumption path.

From (10) and (11), the marginal rate of substitution between currency and deposits, $h_{d} / h_{m}$, would equal $\rho$ if holding a unit of deposits was just equivalent to holding $\rho$ units of currency and (1-p) units of capita1. This equivalence fails because deposits, unlike capital, yield transaction services at the rate $\delta \psi$ and, if $\tau_{1} \neq \tau_{2}$, the tax treatment of income from capital held directly by individuals differs from the treatment of income from capital held by banks. Nominal capital gains on directly held capital are taxed at the rate $\tau_{2}$ while nominal capital gains on the capital held by banks is paid out to depositors and taxed at the rate $\tau_{1}$. If these two tax rates differ, this unequal tax treatment affects the opportunity cost of holding deposits when $\pi \neq 0 .{ }^{6}$

It will be useful in preparation for the analysis of optimal policy in the next section to determine how steady state utility is affected by the three policy variables $\pi, \rho$, and $i$. In order to highlight the tax effects induced by inflation when the opportunity cost of currency is held constant, the monetary authority's policy instruments will be taken to be $\pi, \rho$ and $r$ since a choice of $i$, given $\pi$, is equivalent to a choice 
of $r$. Assuming real currency and bank reserve balances cannot be directly taxed, $i$ must be nonnegative so that any choice of $\pi$ and $r$ is constrained by the requirement that $r \geq-\pi$ with equality if $i=0$.

Making use of (10)-(13), it can be shown that

$$
\begin{aligned}
\partial u / \partial \pi & =u^{\prime}\left\{h_{m} m_{\pi}+h_{d} d_{\pi}\right\} \\
& =\mu\left\{\delta(1+\psi) k_{\pi}^{a}+\delta m_{\pi}+\delta(p-\psi(1-p)) d_{\pi}-\tau_{2} k^{a}+(1-p)\left(\tau_{2}-\tau_{1}\right) d\right\} \\
\partial u / \partial r & =\mu\left\{\delta(1+\psi) k_{r}^{a}+\delta m_{r}+\delta(p-\psi(1-p)) d_{r}+m+\rho d\right\} \\
\partial u / \partial p & =\mu\left\{\delta(1+\psi) k_{p}^{a}+\delta m_{\rho}+\delta(p-\psi(1-p)) d_{\rho}+\left(r-n+\left(\tau_{1}-\tau_{2}\right) \pi\right) d\right\}
\end{aligned}
$$

where $k_{\pi}^{a}=\partial k^{a} / \partial \pi, m_{\pi}=\partial m / \partial \pi$, etc. Equations (14)-(16) will be used in the next section to evaluate the necessary conditions which must be satisfied by the optimal policy.

\section{OPTIMAL POLICY WITH INTEREST ON RESERVES AND CURRENCY}

The fiscal authority is assumed to choose a level of real purchases, $g$, and the tax rates $\tau_{1}$ and $\tau_{2}$. The monetary authority is then constrained by the consolidated government budget identity which requires all deficits to be financed by base money creation. Total expenditures are equal to $g$ plus interest payments on base money, $i(m+\rho d)$. Tax revenues equal $\tau_{1} f\left(k^{a}\right)+\tau_{2} \pi k^{a}+\tau_{1} i(m+p d)+\left(\tau_{1}-\tau_{2}\right)(1-p) \pi d$. If $\theta$ is the rate of growth of base money, $g-\tau_{1} f\left(k^{a}\right)-\tau_{2} \pi k^{a}+\left(1-\tau_{1}\right) i(m+p d)-$ $\left(\tau_{1}-\tau_{2}\right)(1-p) \pi d=\theta(m+p d)$. In the steady state, $\theta=\pi+n$ so the government's budget constraint can be written as 
(17)

$g+(r-n)(m+\rho d)-\tau_{1} f\left(k^{a}\right)-\tau_{2} \pi k^{a}+\left(\tau_{1}-\tau_{2}\right)(1-p) \pi d=0$

The values chosen by the monetary authority for its policy instruments, $\pi, p$, and $r$ must satisfy (17).

An optimal policy is defined as a choice of $(\pi, r, \rho)$ which maximizes the steady state utility of the representative individual subject to (10)-(13), the household sector's budget constraint, the government's budget constraint (17), and the requirement that $\rho$ and $i$ be nonnegative $(r \geq-\pi)$.

Equations (14)-(16) give the partial derivatives of steady state utility with respect to the policy variables. Letting $\zeta$ be the Lagrangian multiplier associated with the government's budget constraint and assuming initially an interior solution with $r+\pi \geq 0$ and $\rho \geq 0$, the first order conditions can be written as

(18) $s\left[\tau_{2} k^{a}+(1-p)\left(\tau_{1}-\tau_{2}\right) d\right]=t_{b} b_{\pi}+t_{d} d_{\pi}+t_{k} k_{\pi}^{a}$

(19) $-s b=t_{b} b_{r}+t_{d} d_{r}+t_{k} k_{r}^{a}$

(20) $s\left[\left(\tau_{2}-\tau_{1}\right) \pi+n-r\right] d=t_{b}\left(m_{\rho}+\rho d_{\rho}\right)+t_{d} d_{\rho}+t_{k} k_{\rho}^{a}$

where $\mathrm{s}=(\mu-\zeta) / \zeta$ is the relative cost of lump-sum taxes to distortionary taxes measured in terms of utility, $\mathrm{t}_{\mathrm{b}}=\mu \delta / \zeta+\mathrm{n}-\mathrm{r}, \mathrm{t}_{\mathrm{d}}=$ $(1-p)\left[\left(\tau_{1}-\tau_{2}\right) \pi-\mu \psi \delta / \zeta\right], t_{k}=\mu \delta(1+\psi) / \zeta+\tau_{1} f^{\prime}\left(k^{a}\right)+\tau_{2} \pi$, and $b=m+p d$ is the monetary base. The form in which (18)-(20) are written high- 
lights the parallel between the optimal choice of monetary policy instruments and the literature on optimal commodity taxation. ${ }^{7}$

The quantity $t_{b}$ is the net tax on base money. The rate of time preference, corrected for the marginal cost of raising revenue through distortionary taxes, plus the rate of population growth represents the cost of holding an additional unit of base money. The difference between this cost and $r$, the after tax real return on currency and reserves, is the net cost of base money, and, since the social cost of producing base money is zero, this difference measures the tax on money. Using (12), this tax can be written as $t_{b}=\left[i_{k}-\psi \delta+s \delta\right]-\left(1-\tau_{1}\right) i$ where $i_{k}$ is the after tax nominal return on capital and the term in brackets is the nominal return on capital net of the value of transaction services necessary to purchase an additional unit of capital and corrected for the cost of distortionary taxes. $\left(1-\tau_{1}\right) i$ is the after tax explicit nominal interest rate on base money. The case normally considered in the literature assumes $i=0$ (no interest paid on base money), $s=0$ (1ump-sum taxes available), and $\psi=0$ (no transaction services explicitly modelled). Under these assumptions, the tax on money is simply the nominal rate of interest $i_{k} \cdot{ }^{8}$

Friedman[1969] argued that the tax on money should be set equal to zero in order to achieve the optimal degree of liquidity. From equation (19),

(21) $t_{b}=-s b / b_{r}-t_{d} d_{r} / b_{r}-t_{k} k_{r}^{a} / b_{r}$. 
If lump-sum taxes are available, $s=0$ and it is likely that $\tau_{\mathbf{1}}=\tau_{\mathbf{2}}=0$. Hence, in this case $t_{b}=\delta+n-r$ and (20) becomes

(22) $t_{b}=(1-p) \psi \delta d_{r} / b_{r}-\left(f^{\prime}-n\right) k_{r}^{a} / b_{r}$

where use has been made of (10) and (12). By noting that (12) implies $\mathrm{k}_{\mathrm{r}}^{\mathrm{a}}=0$ if $\psi=0$, and (10) implies $\psi=0$ if $\delta=\mathrm{n}-\mathrm{r}$, it follows that (22) is satisfied when $t_{b}=0$. This is essentially Phelp's result: if nondistortionary taxes are available, the optimal tax on outside money should be zero, and the real after tax return on currency and reserves should be set equal to $\delta+n$, the after tax return on capital.

With only distortionary taxes, $s \leq 0$ and $t_{b}$ will generally be nonzero. The optimal value of $t_{b}$ is given by equation (21). The first term in (21) parallels the standard partial equilibrium result for the optimum commodity tax. In the present case, the optimum tax is inversely proportional to the own interest rate effect on the demand for base money. If the cross-elasticities embodied in $\mathrm{d}_{\mathrm{r}}$ and $\mathrm{k}_{\mathrm{r}}^{\mathrm{a}}$ are ignored and the two rates $\tau_{1}$ and $\tau_{2}$ are assumed equal, then (21) can be manipulated to show that the optimal after tax real return on base money is equal to $[\delta(1+s)+n] /\left[1-s / \varepsilon_{b, r}\right]$, where $\varepsilon_{b, r}$ is the elasticity of $b$ with respect to $r$. To evaluate this expression, an estimate of $\varepsilon_{b, r}$ is needed. Since neither currency nor reserves have recently earned explicit interest in the U.S., an estimate must be inferred from evidence on the elasticity of currency and reserves with respect to interest rates on alternative nonmoney assets. 
Because $b=m+\rho d, \varepsilon_{b, r}=\varepsilon_{m, r}(m / b)+\varepsilon_{d, r}(1-(m / b))$. Currency constitutes roughly $70 \%$ of the monetary base, so $\mathrm{m} / \mathrm{b} \simeq .7$. Goldfeld[1976] found the long-run elasticity of currency with respect to the rate on time deposits to be -0.19 . If own elasticities exceed cross elasticities, 0.25 might represent a reasonable estimate of $\varepsilon_{\mathrm{m}, \mathrm{r}}$. Interpreting d broadly to incorporate both demand and time deposits, Goldfeld's results would imply a value for $\varepsilon_{d, r}$ of approximately $0.51 .^{9}$ Taken together this implies $\varepsilon_{b, r} \simeq 0.33$. If $\delta=0.04, n=0.01$, and $s=-0.3,{ }^{10}$ the optimal real return on currency and reserves is 0.02 . This is a relatively high real, after tax return. For comparison, the real before tax return on 3-month Treasury bills averaged only 0.008 during 1960:1 $1982: 4$. If $r=0.02$, the tax rate on base money, $t_{b}$, is 0.018 .

If $d_{r}$ and $k_{r}^{a}$ are not equal to zero, this estimate of $r$ must be adjusted to take into account the last two terms in equation (21). If $\tau_{1}$ $\geq \tau_{2}$ and $\pi \leq 0$ (as we shall see is likely to be the case for the optimal $\pi)$, then $t_{d} \leq 0$. The optimal tax on deposits is actually a subsidy. This is so for two reasons. Because $p d$ is a component of $b$ and is taxed at the rate $t_{b}, t_{d}$ is really the tax on bank holdings of capital. If the tax on nominal capital gains on directly held capital is less than the tax rate on other components of income, deflation results is a tax advantage to holding capital indirectly via bank deposits. In addition, such indirectly held capital has a higher social marginal product because it yields transaction services which directly held capital does not provide. Hence, if $d_{r}$ and $b_{r}$ are positive, $t_{d} d_{r} / b_{r} \leq 0$ if $\pi \leq 0$ and this tends to raise the optimal $t_{b}$ (lower $r$ ) in order to partially offset the subsidy going to bank capital by reducing the return on bank reserves. 
Using the same parameter values as before and continuing to ignore the last term in (21), it can be shown that $r \simeq 0.02+.486 \pi-.061 \psi$. The optimal $r$ rises with $\pi$ to offset the resulting tax increase on deposits, and declines with $\psi$, the value of the transaction services yielded by currency and deposits. For example, if the rate of inflation is 0.05 and $\psi$ equals $0.1, r$ rises to 0.038 . If $\pi=-0.05, r$ falls to -0.012 . Since $r$ must exceed $-\pi$, however, this last result suggests that a corner solution may occur if the optimal value of $\pi$ is negative. If a high rate of deflation is necessary to achieve the optimal capital-labor ratio, the real return on base money resulting from the deflation may be sufficiently large that no explicit interest payments on the monetary authority's liabilities are necessary.

The effect of the last term in (21), $\mathrm{t}_{\mathrm{k}} \mathrm{k}_{\mathrm{r}}^{\mathrm{a}} / \mathrm{b} \mathrm{r}$, is more difficult to judge. A portfolio substitution argument would suggest that $\mathrm{k}_{\mathrm{r}}^{\mathrm{a}} \leq 0$. As Stockman[1981] shows, however, an increase in money holdings leads to a rise in the net of transaction costs return to capital and can lead to a rise in the capital-labor ratio. A negative value for $\mathrm{k}_{\mathrm{r}}^{\mathrm{a}}$ will increase the optimal $t_{b}$ and lower $r$.

To further consider the possibility of a corner solution in which (21) would no longer apply, we must examine equation (18), the first order condition for the optimal choice of $\pi$.

When the banking sector's zero profit condition is incorporated into the household sector's budget constraint, the later becomes $\left(1-\tau_{1}\right) f\left(k^{a}\right)-\tau_{2} \pi k^{a}-n k^{a}+(r-n) b-\left(\tau_{1}-\tau_{2}\right)(1-\rho) \pi d-c=0$. Consequent $1 y, \pi$ 
acts as a tax on a base of $\tau_{2} k^{a}+\left(\tau_{1}-\tau_{2}\right)(1-\rho) d$ and this explains the form of the left hand side of (18). Since $r$ is also being optimally set (if the solution is an interior one), $\pi$ does not act as a $t a x$ on base money as in standard analyses.

Examining first the case in which $\tau_{1}=\tau_{2}$, (18) can be rewritten, using the definitions of $t_{k}$ and $t_{d}$, as

(23) $\pi^{\prime}=-f^{\prime}+s k^{a} / k_{\pi}^{a}-t_{b} b_{\pi} / \tau_{1} k_{\pi}^{a}+(1+s) \delta \psi(1-p) d_{\pi} / \tau_{1} k_{\pi}^{a}-(1+s) \delta(1+\psi)$

where $\pi^{\prime}$ is the optimal rate of inflation. Friedman's conclusion in a static framework was that the optimal rate of deflation equaled the marginal product of capital, thereby reducing the opportunity cost of holding money to zero. The first term in (23), $-f^{\prime}\left(k^{a}\right)$, appears for a different reason. Since $r$ can be adjusted to produce the desired degree of liquidity (assuming an interior solution), $\pi$ is set to achieve the optimal tax on capital income. The choice of $\pi$ then determines the steady state capital-labor ratio. If $\pi=-f^{\prime}$, the after tax real return on capital is simply $f^{\prime}$ and the effective tax on capital is zexo. If the sum of the last four terms in (23) is positive, capital is taxed. This role of $\pi$ in affecting $k^{a}$ is somewhat similar to that discussed by Summers[1981]. In his mode1, which assumed a fixed savings rate so that $k$ was not optimally chosen, a rate of inflation greater than - $f^{\prime}$ could maximize welfare by inducing a substitution of capital for money, thereby raising the steady state capital-labor ratio. However, such an increase in the rate of inflation above - $f^{\prime}$ simultaneously raises the private opportunity cost of holding money above its social cost of 
production. In the present model, $r$ can be adjusted to achieve the desired opportunity cost of liquidity. Note, however, that $\pi \leq-f^{\prime}$ implies $r \geq f^{\prime}$ which is inconsistent with an equilibrium in which both capital and money are held.

To provide some orders of magnitude figures to the rate of inflation implied by equation (23), suppose $f^{\prime}=0.1, f\left(k^{a}\right)=\left(k^{a}\right) \cdot 25$, and assume $\partial \psi / \partial \pi \simeq 0$. With these assumptions, together with the parameter values used earlier, (23) becomes

$$
\pi \simeq-.139+.0007 b_{\pi} / b-.0003 d_{\pi} / d
$$

where .07 has also been used as a rough estimate of $b / k^{a}$, and $t_{b}$ has been set equal to 0.02 . The sign of $d_{\pi}$ is ambiguous if $\tau_{1} \geq \tau_{2}$, since a rise in $\pi$ reduces the return to deposits via the tax effect but simultaneously raises the return on reserves relative to capital. Because $b_{\pi}=$ $\mathrm{m}_{\pi}+\rho \mathrm{d}_{\pi}, \mathrm{b}_{\pi}$ is also ambiguous in sign, although it is more likely to be positive. In any case, the last two terms in (24) are likely to be small so that the implied optimal rate of inflation is of the order of -.10 .

Such high rates of deflation, however, are inconsistent with the assumption that $r$ is held fixed. This suggests that the optimal policy is likely to be at a corner solution in which the nominal interest rate on currency and bank reserves is set equal to zero. This is consistent with Feldstein's argument that the tax effects of inflation dominate any inefficiencies produced by a divergence between the private and social 
opportunity costs of base money (Feldstein[1976]). Calls for the payment of interest on central bank liabilities may not be warrented if the income tax system taxes the nominal return to capital and the inflation rate is chosen optimally.

If $i$ cannot be adjusted to keep $r$ constant as $\pi$ is varied, the effect of a change in $\pi$ on steady state utility is $d u / d \pi=\partial u / \pi-\partial u / \partial r$, and the first order condition for the optimal choice of $\pi$ becomes,

(25) $s\left[\tau_{2} k^{a}+\left(\tau_{1}-\tau_{2}\right)(1-p) d+b\right]=t_{b}\left(b_{\pi}-b_{r}\right)+t_{d}\left(d_{\pi}-d_{r}\right)+t_{k}\left(k_{\pi}^{a}-k_{r}^{a}\right)$

which can be compared with (18). On the left side of (25), the tax base subject to an inflation tax now includes $b$. On the right side, the terms $b_{\pi}-b_{r}, d_{\pi}-d_{r}$, and $k_{\pi}^{a}-k_{r}^{a}$ now appear to capture the two channels by which $\pi$ affects holdings of currency and deposits. Equation (25) implies that

$$
t_{k}=t_{k}^{\prime}+\left(s b+t_{b} b_{r}+t_{d} d_{r}+t_{k} k_{r}^{a}\right) / k_{\pi}^{a}
$$

where $t_{k}{ }^{\prime}$ is the expression for $t_{k}$ when $i \geq 0$. It can be shown that the second term in (26) has the same sign as $-k_{\pi}^{a}$. With $k_{\pi}^{a} \leq 0, t_{k} \geq t_{k}{ }^{\prime}$. The inability to offset the liquidity effects of a variation in $\pi$ means that a higher tax on capital is necessary at the optimum. This is achieved with a higher rate of inflation (smaller, in absolute value, rate of deflation). For plausible parameter values, however, the effect is likely to be quite small. 
The monetary authority's final tax instrument, the required reserve ratio, is, like $r$, important in influencing the composition of liquidity holdings by the public between directly held currency and indirectly held bank reserves. The after tax real return on deposits is a weighted average of the returns on reserves and bank capital with weights $\rho$ and (1-p) respectively. If the return on bank holdings of capital exceeds the return on reserves, this rate of return differential on the two sources of liquidity will lead individuals to economize on the use of currency relative to deposits. This social inefficiency was discussed by Johnson[1968] who viewed it as arising when currency paid no nominal return. It continues to occur even if, as in the present case, reserves and currency pay a nominal return less than that available to banks from holding capital. This inefficiency can be reduced by the monetary authority if it optimally sets $\rho$. Note that $\rho=0$ maximizes the return differential between currency and deposits but (when $\tau_{1}=\tau_{2}$ ) minimizes the differential between the returns on deposits and capital. At the other extreme, $p=1$ forces the yields on deposits and currency to be equal but maximizes the spread between the yields on capital and deposits.

Equation (20) can be rewritten as

(27) $t_{d}=-\rho t_{b}+s\left[n-r+\left(\tau_{2}-\tau_{I}\right) \pi\right] d / d{ }_{\rho}-t_{b} m_{\rho} / d_{\rho}-t_{k} k_{\rho} / d$

where $\left[n-r+\left(\tau_{1}-\tau_{2}\right) \pi\right] d$ is the partial derivative of the government's deficit with respect to $\rho$. The total tax on deposits is given by $t_{d}+\rho t_{b}$ which, from (27), is 
(28) $t_{d}+\rho t_{b}=s\left[n-r+\left(\tau_{1}-\tau_{2}\right) \pi\right] d / d_{p}-t_{b} m_{p} / d_{\rho}-t_{k} k_{p}^{a} / d_{\rho}$.

The first term in (28) corresponds to the standard expression for an optimal commodity tax in the absence of cross demand effects. Since $m_{\rho}$ and $d_{p}$ are likely to be of opposite sign, the second term in (28) tends to increase the optimal tax on deposits since individuals are able to substitute currency for deposits in the production of liquidity. Assuming $\tau_{1} \geq \tau_{2}$ and $\pi \leq 0$ at the optimum, the tax on deposits varies positively with $p$.

Equation (28) can be used to evaluate the optimal value of $\rho$ if it is assumed, for purposes of illustration, that $\tau_{1}=\tau_{2}, k_{\rho}^{a}=0$, the elas ticity of $d$ with respect to $\rho$ is -1 and that of $m$ with respect to $\rho$ is +1. In this case, with $\mathrm{m} / \mathrm{d} \simeq .07, i=0$ and $\pi$ set equal to -.10 , the optimal reserve ratio is approximately $11 \%$. This is above the current ratio of required reserves to time deposits and about equal to the ratio of required reserves to large transaction accounts.

While the first order conditions for each of the monetary authority's three tax instruments have been discussed individually, the optimal values of $\pi, \rho$, and $r$ must generally be determined simultaneously. This is obviously the case when, as seemed likely, a corner solution in which $i$ $=0$ occures.

\section{OPTIMAL POLICY WITH NO INTEREST PAID ON CURRENCY}


The payment of interest on bank reserves is certainly technologically feasible; the payment of interest on currency may not be. This section briefly examines optimal policy when the monetary authority pays interest only on the reserve component of base money. The results of the previous section suggested that a corner solution might occur in which nominal interest is paid on neither reserves nor currency. In this case, the restriction the $i$ be paid only on reserves is irrelevant. It is useful, however, to study the form of the interior solution when interest is paid only on reserves. The failure of currency to earn an explicit rate of interest will tend to increase the demand for bank deposits, relative to currency, as a means of producing liquidity. However, the extent to which this substitution of deposits for currency takes place is dependent on the monetary authority's setting of its policy instruments. The attractiveness of holding money in the form of deposits rather than currency will depend on both the rate of interest paid on reserves and the reserve requirement ratio. In addition, a change in $\pi$ now has a direct effect on the real return on currency as well as on the rate of return on capital.

The first order conditions for the representative individual's maximization problem now take the form, in equilibrium,

$$
\begin{aligned}
\psi \mathrm{h}_{\mathrm{m}} & =\delta+\mathrm{n}+\pi \\
\psi \mathrm{h}_{\mathrm{d}} & =\rho(\delta+\mathrm{n}-\mathrm{r})+(1-\rho)\left[\left(\tau_{1}-\tau_{2}\right) \pi-\psi \delta\right] \\
\mathrm{h}(\mathrm{m}, \mathrm{d}) & =\left(1-\tau_{1}\right) f\left(\mathrm{k}^{\mathrm{a}}\right)-\left(\tau_{2} \pi+\mathrm{n}\right) \mathrm{k}^{\mathrm{a}}+(1-\rho)\left(\tau_{1}-\tau_{2}\right) \pi \mathrm{d}+(\mathrm{r}-\mathrm{n}) \rho \mathrm{d}-(\pi+\mathrm{n}) \mathrm{m}
\end{aligned}
$$


$\left(1-\tau_{1}\right) f^{\prime}\left(k^{a}\right)-\tau_{2} \pi=\delta(1+\psi)+n$

The monetary authority's revenue constraint is given by

$g-\tau_{1} f\left(k^{a}\right)-\tau_{2} \pi k^{a}+(r-n) d-(\pi+n) m-\left(\tau_{1}-\tau_{2}\right)(1-p) \pi d=0$

With these modifications, the first order conditions for the optimal choice of $\pi, p$, and $r$ can be written as

$$
\begin{aligned}
& s\left[m+\tau_{2} k^{a}+\left(\tau_{1}-\tau_{2}\right)(1-p) d\right]=t_{b}{ }^{\prime} m_{\pi}+t_{d} d_{\pi}+t_{k} k_{\pi}^{a} \\
& -s p d=t_{b}{ }^{\prime} m_{r}+t_{d} d_{r}+t_{k} k_{r}^{a} \\
& s\left[\left(\tau_{2}-\tau_{1}\right) \pi+n-r\right]=t_{b}{ }^{\prime} m_{p}+t_{d} d_{p}+t_{k} k_{p}^{a}
\end{aligned}
$$

where $t_{b}{ }^{\prime}=\mu \delta / \zeta+n+\pi$, and $t_{d}$ and $t_{k}$ are defined as before.

Comparing (29)-(31) to the first order conditions obtained when interest was paid on both reserves and currency, equations (18)-(20), reveals several important differences. As (29) makes clear, the revenue base subject to an inflation tax now includes $\mathrm{m}$, real currency holdings. This factor alone, by raising the marginal revenue yield of an increase in $\pi$ would raise the optimal rate of inflation. However, changes in $\pi$, given $r$, simultaneously increase both $t_{k}$ (as before) and $t_{b}{ }^{\prime}$ and affect not only the choice between capital and liquidity, but also the choice between deposits and currency even when $\tau_{1}=\tau_{\mathbf{2}}$. Reducing the social inefficiency in the provision of deposit services generated by inflation 
would lower the optimal rate of inflation below that obtained in the previous section when currency yielded explicit interest.

Because $r$ is paid only on reserves, spd appears on the left side of (30), rather that $s b=s(m+p d)$ as in (19). The results obtained for the earlier case are modified in two ways. First, paying interest only on reserves reduces the marginal revenue cost of paying interest; this should tend to increase the optimal value of $r$. The second modification is due to the distortions introduced in the deposit/currency choice by the payment of interest only on reserves. Accounting for this effect would tend to lead to a higher tax on deposits (a lower $r$ ).

Equations (31) and (20) are identical in form although the definition of the tax on currency differs as $t_{b}{ }^{\prime}=t_{b}+\left(1-\tau_{1}\right) i$. Since $t_{b}{ }^{\prime} \geq t_{b}$ for any $r$ and $\pi$, the higher tax rate on currency, considered in isolation, tends to increase the optimal reserve ratio on deposits.

\section{SUMMARY AND CONCLUSIONS}

This paper has utilized an optimal taxation framework to analyze the choice by the monetary authority of its policy instruments. These instruments, the rate of inflation in the steady state, the interest rate on reserves and currency, and the reserve requirement ratio on deposits, all have characteristics in common with commodity taxes. By its choice of policy instruments, the monetary authority can affect the rates of return on capital, bank deposits, and currency. In general, the optimal rate of inflation is not independent of the interest rate paid on base money or the required reserve ratio. 
Unlike previous analyses of the optimal rate of inflation, the model used in this paper assigns distinct roles to explicit interest on base money and the rate of inflation. The former is set to achieve the optimal opportunity cost of liquidity, while the latter is used to achieve the optimal capital-labor ratio. However, the analysis suggests that the optimal nominal interest rate on the central bank's liabilities may be zero. More importantly, any discussion of the payment of interest on reserves and currency must take into account the nature of the tax system and the rate of inflation in a nonindexed world. 


\section{FOOTNOTES}

1. See also Green and Sheshinski[1977] and Drazen[1979].

2. Also relevant is the paper by Weiss [1980].

3. A subscript $i$ on a function denotes the partial derivative with respect to its ith argument. Note that $h_{m}$ and $h_{d}$ are assumed to be strictly positive. For a similar approach, see Grandmont and Yonnes[1973]. This framework ignores the role of trade inventories, emphasized by Clower[1970].

4. Because only steady state equilibria are considered, no distinction is made between actual and expected inflation.

5. See Benhabib and Bull[1983] for an analysis of optimal inflation a1long the path to the steady state.

6. It is interesting to contrast the equilibrium conditions (10)-(13) with those which would arise if a money-in-the-utility function approach had been adopted. If $u=u(c, h(m, d))$, for example, $\psi$ is replaced by $u_{h} / u_{c}$ in (10) and (11) while $\psi$ drops out of (12). In this case, for given $r$ and $\rho, \pi$ affects $k^{a}$ if and only if $\tau_{2} \neq 0$. If the tax system is indexed, money is superneutral (see Sidrauski[1967]). In addition, $k_{r}^{a}=k_{p}^{a}=0$. The cash-in-advance approach leads to real effects of $r, \rho$, and $\pi$ even if $\tau_{2}=0$. 
7. For example, compare (18)-(20) with equation (7), page 41 of Sand$\operatorname{mo}[1976]$.

8. As pointed out by Phelps[1973], the 'tax rate' in the inflation tax is the nominal rate of interest, not the rate of inflation.

9. If $m+d$ is identified with $M_{2}, \varepsilon_{M_{2}}=\varepsilon_{M, r}\left(r / M_{2}\right)+\varepsilon_{d, r}\left(d / M_{2}\right)$. d/M 2 is approximately 0.93 while Goldfeld finds the elasticity of $M_{2}$ with respect to the rate on time deposits to be 0.49 . If $\varepsilon_{\mathrm{m}, \mathrm{r}}=0.25$, this implies $\varepsilon_{d, r} \approx 0.51$.

10. Ballard, Shoven, and Whalley[1982] estimate the deadweight loss from distortioary taxes to range from $\$ 0.34$ to $\$ 0.48$ per dollar of revenue. Taking $\$ 0.40$ as an estimate implies $s=1 / 1.4-1 \simeq-0.3$. 


\section{REFERENCES}

1. Atkinson, A. B, and J. E. Stigiltz, "The Structure of Indirect Taxes and Economic Efficiency", Journal of Public Economics 1, No. 1 (April 1972), 97,119

2. Atkinson, A. B, and J. E. Stiglitz, "The Design of Tax Structure: Direct versus Indirect Taxation, Journal of Public Economics 6, Na. 1,2 (July-August 1976), 55-75

3. Auerbach, Alan J., "Taxation, Corporate Financial Policy and the Cost of Capital", Jaurnal of Economic Literature 21, Na. 3 (September 1983), 905-940.

4. Ballard, Gharles L., John B, Shoven, and John Whalley, "The Welfare Cost of Distortions in the United States Tax System: A General Equilibrium Approach", National Bureau of Economic Research Working Paper No. 1043 (December 1982).

5. Baumol, William J. and David F. Bradford, "Optimal Departures from Marginal Cost Pricing", American Economic Review 60, No. 3 (June $1970), 265+283$. 
6. Benhabib, Jess and Clive Bu11, "The Optimal Quantity of Money: A Formal Treatment", Internation Economic Review 24, No. 1 (February 1983), 101-111.

7. Clower, Robert W. "A Reconsideration of the Microfoundations of Monetary Theory", Western Economic Journal 6, No. 1 (December 1967), $1-9$.

8. Clower, Robert W., "Is There an Optimal Money Supply?", Journal of Finance 25, No. 2 (May 1970), 425-433.

9. Deaton, Angus, "The Distance Function in Consumer Behaviour with Applications to Index Numbers and optimal Taxation", The Review of Economic Studies 46, No. 3 (July 1979), 391-405.

10. Diamond, Peter A. and James A. Mirrlees, "Optimal Taxation and Public Production I-II", American Economic Review 61, I is in No. 1 (March 1971), 8-27, II is in No. 2 (June 1971), 261-278.

11. Drazen, Allan, "The Optimal Rate of Inflation Revisited", Journal on Monetary Economics 5, No. 2 (April 1979), 231-248.

12. Fama, Eugene, "Banking in the Theory of Finance", Journal of Monetary Economics 6, No. 1 (January 1980), 39-57.

13. Feldstein, Martin, "The Welfare Cost of Capital Income Taxation", Journal of Political Economy 86, No. 2, pt. 2 (April 1978), 529-551. 
14. Feldstein, Martin, "The Welfare Cost of Permanent Inflation and Optimal Short-Run Economic Policy", Journal of Political Economy 87, No. 4 (August 1979), 749-768.

15. Fischer, Stanley, "Money and the Production Function", Economic Inquiry 12, No. 4 (December 1974), 517-533.

16, Friedman, Milton, "The Optimum Quantity of Money," in The Optimum Quantity of Money and Other Essays Aldine, Chicago, 1969.

17. Grandmont, J. M. and Y. Younes, "On the Efficiency of a Monetary Equilibrium", The Review of Economic Studies 40, No. 2 (April 1973), $149-165$.

18. Green, Jerry, and Eytan Sheshinski, "Budget Displacement Effects of Inflationary Finance", American Economic Review 67, No. 4 (September 1977), 771-782.

19. Helpman, Elhanon, and Ednaim Sadka, "Optimal Financing of the Government's Budget: Taxes, Bonds, or Money?", American Economic Review 69, No. 1 (March 1979), 152-160.

20. Johnson, Harry G., "Problems of Efficiency in Monetary Management", Journal of Political Economy 76, No. 5 (September/October 1968), 971-990.

21. Johnson, Harry G., "Is There an Optimal Money Supply?", Journal of Finance 25, No. 2 (May 1970), 435-442. 
22. Marty, Alvin L., "Inflation, Taxes and the Public Debt", Journal of Money, Credit, and Banking 10, No. 4 (November 1978), 437-452.

23. McCallum, Bennett, "The Role of Overlapping Generations Models in Monetary Economics" in Money, Monetary Policy, and Financial Institutions K. Brunner and A. H. Meltzer (eds.) CarnegieRochester Conference Series on Public Policy, vol. 18 (Spring 1983).

24. Phelps, Edmund S., "Inflation in the Theory of Public Finance", Swedish Journal of Economics (March 1973), 67-82.

25. Sandmo, Agnar, "Optimal Taxation - An Introduction to the Literature", Journal of Public Economics 6, No. 1,2 (July-August 1976), 37-54.

26. Sidrauski, Migue1, "Rational Choice and Patterns of Growth in a Monetary Economy", American Economic Review 58, No. 4 (May 1967), 534-544.

27. Siegel, Jeremy J., "Notes on Optimal Taxation and the Optimal Rate of Inflation", Journal of Monetary Economics 4, No. 2 (April 1978), 297-305.

28. Stockman, Alan C., "Anticipated Inflation and the Capital Stock in a Cash-in-Adyance Economy", Journal of Monetary Economics 8, No. 3 (November 1981), 387-393. 
29. Summers, Lawrence H., "Optimal Inflation Policy", Journal of Monetary Economics 7, No. 2 (March 1981), 175-194.

30. Weiss, Laurence, "The Effects of Money Supply on Economic Welfare in the Steady State", Econometrica 48, No. 3 (April 1980), 565-576. 